\title{
Direitos humanos e linguísticos e suas relações com a educação de surdos: reflexões a partir do diálogo com estudantes surdos fluentes em Libras
}

\author{
Human and linguistic rights and their relationship with deaf education: \\ reflections from the dialogue with deaf students fluent in Libras
}

\begin{abstract}
D Ivone Maria Mendes Silva
Pós-doutoranda em Educação pela Universidade de São Paulo (USP). Doutora em Psicologia pela Universidade de São Paulo (USP). Professora adjunta da Universidade Federal da Fronteira Sul (UFFS), Campus Erechim, RS, Brasil. ivonemmds@gmail.com

iD Silvia Salete Remos

Pós-Graduanda em Libras e em Psicopedagogia pela Uniasselvi. Licenciada em Pedagogia pela Universidade Federal da Fronteira Sul (UFFS), Campus Erechim. Atua como Tradutora e Intérprete de Libras na Câmara de Vereadores de Erechim e no Instituto Federal de Educação, Ciência e Tecnologia do Rio Grande do Sul, Brasil. silvia.remos@hotmail.com
\end{abstract}

Resumo: Este artigo apresenta reflexões sobre o papel que os direitos humanos e linguísticos podem desempenhar como elementos estruturantes da educação escolar oferecida aos surdos. Abarca contribuições de teóricos das ciências humanas e sociais, além da análise das narrativas de estudantes surdos sobre a importância da Língua de Sinais para seus processos de construção de conhecimento na escola e em outras esferas da vida social. O instrumento de pesquisa utilizado foi a entrevista individual, realizada em Libras, com quatro sujeitos surdos. Os dados foram analisados de acordo com pressupostos da Análise de Conteúdo de Laurence Bardin. Com base nos resultados, conclui-se que a Libras ocupa lugar central na vida dos entrevistados, sendo por eles significada como um direito cujo usufruto repercute no exercício de outros direitos (educacionais, culturais, políticos etc.). Não obstante, ainda precisa ocorrer uma maior difusão e valorização de seu uso nas/pelas escolas, assim como em outros espaços públicos.

Palavras-chave: Educação de surdos. Surdez. Língua de Sinais. Direitos humanos. Direitos Linguísticos.

Abstract: This article presents reflections on the role that human and linguistic rights can play as structural elements of school education offered to the deaf. For this, part of the theoretical contributions of scholars of the theme, in addition to the analysis of narratives of deaf students about the importance of Sign Language for their processes of building knowledge in school and participating in social life. To obtain the narratives, individual interviews were conducted, in Lingua de Signals, with four deaf subjects. The data were analyzed according to the assumptions of Laurence Bardin's Content Analysis. Based on the results, it is concluded that Libras occupies a central place in the interviewees' lives, being meant by them as a right whose enjoyment has an impact on the exercise of other rights (educational, cultural, political, etc.). However, there still needs to be a greater diffusion and appreciation of its use in/by schools, as well as in other public spaces.

Keywords: Deaf education. Deafness. Sign language. Human rights. Linguistic Rights. 


\section{Dialogia}

SILVA, Ivone Maria Mendes; REMOS, Silvia Salete. Direitos humanos e linguísticos e suas relações com a educação de surdos: reflexões a partir do diálogo com estudantes surdos fluentes em Libras

Introdução

Inúmeros aspectos da educação voltada às pessoas com surdez constituem, na atualidade, objeto de interesse e preocupação do Estado e de diferentes setores da sociedade, sendo que alguns deles ainda encerram desafios a serem superados. A abrangência e relevância desses processos pode ser mais bem estimada se levarmos em conta que mais de nove milhões de brasileiros possuem deficiência auditiva, segundo dados do Censo Demográfico de 2010 (BRASIL/IBGE, 2012).

Um importante marco na história das comunidades surdas brasileiras foi o reconhecimento da Língua Brasileira de Sinais - Libras como língua oficial pela Lei $\mathrm{N}^{\circ}$ 10. 436, de 24 de abril de 2002, regulamentada pelo Decreto 5.626, de 22 de dezembro de 2005. Ele se soma a outras ações do Estado e a iniciativas de diferentes setores da sociedade civil e dos próprios movimentos surdos para garantir a conquista de direitos que até então vinham sendo negados a esse público, dentre eles: o direito de estudar em escolas bilíngues na Educação Infantil e nos anos iniciais do Ensino Fundamental, escolas bilíngues ou escolas regulares abertas nos anos finais do Ensino Fundamental, médio ou profissionalizante, bem como a presença do tradutor/intérprete de Libras/português nessas instituições. Além disso, esses sujeitos passaram a contar também com o direito a atendimento educacional especializado para complementação curricular, o uso e a difusão da Libras, dentre outros avanços (BRASIL, 2002; BRASIL, 2005; BRASIL, 2015).

Conquistas como essas decorrem de muitas lutas sociais e ensejam não apenas o reconhecimento da Língua de Sinais como forma de comunicação, expressão e transmissão de conhecimentos pelos surdos, mas também a legitimação da sua participação na sociedade como sujeitos de direitos.

Não obstante, cabe lembrarmos que a cultura e a língua da comunidade surda são desconhecidas para grande parte da população brasileira, o que representa um obstáculo para a inserção social e escolar desses sujeitos. Além disso, o reconhecimento dos direitos fundamentais dos estudantes surdos, em nosso país, ainda não tem se convertido satisfatoriamente no acesso a ações, oportunidades e serviços que, ao contemplarem suas necessidades específicas, lhes permitam o exercício da cidadania plena e da autonomia. Essa realidade pode ser constatada tanto no âmbito da educação básica quanto no ensino superior e se relaciona com questões estruturais do sistema escolar brasileiro, mas também com problemas mais abrangentes que historicamente marcam a nossa sociedade e redundam em desigualdades e violações dos direitos humanos.

Levando em consideração esse cenário, bem como outras reflexões suscitadas pelos debates acadêmicos e sociais atualmente existentes sobre o tema, buscamos problematizar, no presente artigo, dados oriundos de uma pesquisa empírica que investigou as narrativas produzidas por 
SILVA, Ivone Maria Mendes; REMOS, Silvia Salete. Direitos humanos e linguísticos e suas relações com a educação de surdos: reflexões a partir do diálogo com estudantes surdos fluentes em Libras

estudantes surdos sobre a importância da Língua de Sinais para seus processos de construção de conhecimento na escola e em outras esferas da vida social.

O artigo está organizado da seguinte forma: após essa introdução, trazemos explanações sobre os direitos humanos e linguísticos e suas relações com a educação, delimitando a discussão em torno da educação de surdos. Posteriormente, são fornecidas informações acerca da metodologia da pesquisa, seguida da apresentação e discussão dos resultados do estudo empírico realizado junto aos estudantes surdos. Por fim, as considerações finais.

O papel dos direitos educacionais e linguísticos na construção da escola como instituição democrática e na educação de surdos

Segundo Norberto Bobbio, a concepção dos direitos humanos como valores norteadores e reguladores da vida social, tão difundida no mundo ocidental, surge atrelada à ideia de democracia, possibilitada pela "ampla e segura participação da maior parte dos cidadãos, em forma direta e indireta, nas decisões que interessam à toda coletividade" (BOBBIO, 1983, p. 55-56). E é somente no âmbito das instituições democráticas que todos, sem distinção de cor, raça, sexo, classe social, religião etc., podem ter acesso a uma educação para a liberdade e para a participação na vida pública, condições necessárias ao exercício da cidadania (BOBBIO, 2001).

Ainda como lembra Bobbio (1992), uma questão central atinente aos direitos humanos refere-se às mudanças sociais ocorridas na contemporaneidade ocidental, em especial a partir das últimas décadas do século XX, que possibilitaram a emergência de novos direitos, calcados sobretudo no reconhecimento e no respeito às diferenças.

Questão cuja problematização é certamente muito cara ao campo educacional, como demonstra Carlota Boto ao discutir especificamente a articulação entre direitos humanos e educação escolar. Inspirando-se na leitura analítica de Bobbio, a autora defende a tese de que "os direitos humanos em educação podem ser concebidos também por gerações” (BOTO, 2005 p.793). Em suas palavras:

[...] o direito à educação se teria desenvolvido em três gerações: 1 . O ensino torna-se paulatinamente direito público quando todos adquirem a possibilidade de acesso à escola pública; 2 . A educação como direito dá um salto quando historicamente passa a contemplar, pouco a pouco, o atendimento a padrões de exigência voltados para a busca de qualidade no ensino oferecido e para o reconhecimento de ideais democráticos internos à vida escolar; 3. O direito da educação será consagrado quando a escola adquirir padrões curriculares e orientações políticas que assegurem inversão de prioridades, mediante atendimento que contemple - à guisa de justiça distributiva - grupos sociais reconhecidamente com maior dificuldade para participar desse direito subjetivo universal - que é a escola pública, gratuita, obrigatória e laica [...] (BOTO, 2005, p. 777). 
Pensar e concretizar a escola como instituição democrática requer considerarmos, portanto, a existência de direitos educacionais de primeira, segunda e terceira geração, buscando compreender as possíveis conexões entre eles, com a consciência de que "mesmo hoje estamos mais próximos de uns do que de outros; uns mais, outros menos”. E isso ocorre em função de fatores sócio-históricos, mas também de decisões políticas (BOTO, 2005, p.793).

Contemplando, nessa discussão, a situação das pessoas com surdez e seu direito à educação, podemos afirmar que, ao terem a possibilidade de frequentarem a escola pública, essas pessoas passam a ter acesso a um direito de primeira geração. Mas, para além de assegurar esse direito, há que se garantir a qualidade do ensino que lhes é oferecido e mais: "revisar a cultura escolar à luz de questões advindas do debate atinente à diversidade", de modo a desconstruir a lógica excludente que ainda se faz presente nos processos de escolarização (BOTO, 2005, p.789).

Em complemento a essa perspectiva, Rodrigues e Beer (2016, p. 670) pontuam outro aspecto relevante da discussão atual em torno da educação de surdos: o fato de que a língua está diretamente atrelada aos direitos humanos, sendo os direitos linguísticos indispensáveis, notadamente no caso das minorias linguísticas, para garantir o acesso e usufruto a outros direitos humanos, como os sociais, políticos, econômicos e culturais. Congruente com isso, cabe reconhecermos o importante papel que os direitos humanos e linguísticos podem desempenhar como "norteadores da educação" dos sujeitos que constituem essas minorias (RODRIGUES, BEER, 2016, p. 663-664). Não por acaso, complementam os autores,

Os surdos reivindicam seus direitos humanos linguísticos ao preconizar o reconhecimento e o respeito à língua de sinais como um elemento central à sua afirmação e visibilidade social, cultural, política e acadêmica. A língua de sinais deve lograr, então, a legitimidade de uso social em todas as esferas, principalmente, na família e na educação (RODRIGUES, BEER, 2016, p. 672).

\section{Metodologia}

O presente estudo, de caráter qualitativo, contou com a participação de duas crianças e dois jovens, moradores da cidade de Erechim/RS. Todos possuem surdez profunda bilateral prélingual, ou seja, não ouvem em ambos os ouvidos desde antes da aquisição de qualquer tipo de língua e se comunicam exclusivamente através da Língua de Sinais.

Os sujeitos foram, ao longo do artigo, identificados por nomes fictícios, de forma a preservar o sigilo sobre suas identidades. Além dessa medida, foram adotados outros procedimentos éticos estabelecidos para a pesquisa científica em Ciências Humanas, como o uso de termos de assentimento informado para as crianças e jovens, demonstrando sua disponibilidade 
SILVA, Ivone Maria Mendes; REMOS, Silvia Salete. Direitos humanos e linguísticos e suas relações com a educação de surdos: reflexões a partir do diálogo com estudantes surdos fluentes em Libras

em cooperar na pesquisa, além de termos de consentimento livre e esclarecido dirigidos aos pais ou responsáveis legais pelas crianças. Outras informações relevantes sobre o perfil dos entrevistados encontram-se descritas no quadro abaixo.

Quadro 1 - Perfil dos participantes da pesquisa

\begin{tabular}{|c|c|c|c|}
\hline $\begin{array}{c}\text { Nome fictício } \\
\text { e idade }\end{array}$ & Escolaridade & $\begin{array}{c}\text { Ocupação/Profissão } \\
\text { atual }\end{array}$ & $\begin{array}{c}\text { Cursa/cursou o Ensino } \\
\text { Fundamental em escola } \\
\text { pública ou privada }\end{array}$ \\
\hline Júlia/11 anos & $\begin{array}{c}\text { Cursando } 4^{\circ} \text { ano do Ensino } \\
\text { Fundamental }\end{array}$ & Estudante & Pública \\
\hline $\begin{array}{c}\text { Marcela/12 anos } \\
\text { Fundamental }\end{array}$ & $\begin{array}{c}\text { Cursando } 5^{\circ} \text { ano do Ensino } \\
\text { Fundica }\end{array}$ & Estudante & Pública \\
\hline $\begin{array}{c}\text { Ana Paula/22 } \\
\text { anos }\end{array}$ & $\begin{array}{c}\text { Cursando Técnico em Finanças } \\
\text { Pedro/31 anos }\end{array}$ & Estagiária & Pública \\
\hline
\end{tabular}

Fonte: Elaborado pelas autoras a partir dos dados obtidos nas entrevistas.

A seleção dos quatro participantes de nosso estudo se deu em função da disponibilidade e interesse dos mesmos em colaborar na realização da pesquisa, constituindo uma "amostra por conveniência", cuja composição baseou-se também na adoção dos seguintes critérios: os sujeitos aos quais fizemos o convite para participar da pesquisa tinham relação direta com o tema da pesquisa e, por isso, grande potencial para contribuir com a mesma; o número de participantes foi suficiente para obtermos a saturação das informações obtidas, tendo a análise destas resultado em uma discussão densa das questões da pesquisa (GOMES, 2008).

Como instrumento de pesquisa foi utilizada a entrevista semiestruturada individual, procedendo-se com a realização de perguntas-chave para facilitar o diálogo e a produção de narrativas pelos sujeitos-participantes, como as seguintes: a) Quando você aprendeu a Lingua de Sinais? b) Com quem você costuma se comunicar nessa língua? c) Quando você comecou a frequentar a escola, já era fluente em Libras? Nesse contexto, como é/ era o uso da Libras, quem utiliza/ utilizava-a? d) Explique o que representa para você se comunicar na Lingua de Sinais, qual a importância de utilizar a Libras.

Cabe ainda elucidar que a realização das entrevistas ocorreu no ano de 2018 e os sujeitos da pesquisa puderam produzir tanto narrativas orais quanto escritas, conforme sua própria escolha. Os jovens (Ana Paula e Pedro) produziram narrativas escritas a partir das perguntas dirigidas a eles, enquanto as crianças (Júlia e Marcela) comunicaram suas respostas diretamente à pesquisadora, segunda autora deste artigo, que é fluente em Libras. Esta, então, procedeu com o registro escrito das narrativas. 
SILVA, Ivone Maria Mendes; REMOS, Silvia Salete. Direitos humanos e linguísticos e suas relações com a educação de surdos: reflexões a partir do diálogo com estudantes surdos fluentes em Libras

Para análise dos dados, baseamo-nos em pressupostos do método de Análise de Conteúdo, seguindo orientações de Bardin (2016) e levando em consideração os apontamentos feitos por Gomes (2012) sobre tais orientações. Como parte do processo de análise, foram empreendidas, num primeiro momento, diversas leituras do material para, na sequência, proceder-se com a organização dos conteúdos por eixos temáticos, sistematizados a partir de suas relações de proximidade/semelhança ou contraste/divergência. Posteriormente foram feitas inferências inspiradas em reflexões críticas sobre a realidade estudada, assim como interpretações fundamentadas no referencial teórico adotado e na problematização de achados obtidos em outros estudos já realizados sobre o tema.

O que pensam estudantes surdos sobre a importância da Língua de Sinais: aportes para uma reflexão sobre direitos linguísticos e sua relação com outros direitos

Antes de iniciarmos a discussão a respeito do que os estudantes surdos que participaram desta pesquisa pensam sobre a importância da Libras, buscaremos situar informações sobre suas trajetórias escolares e de aprendizado da Língua de Sinais.

Assim, podemos destacar que eles têm em comum o fato de pertencerem a famílias ouvintes e de terem frequentado a Associação de Pais e Amigos dos Deficientes Auditivos do Alto Uruguai (APADA). Essa associação, além de oferecer diversas formas de apoio aos familiares de surdos, tem o papel social de ensinar e difundir a Língua de Sinais em sua região de abrangência.

Pedro (31 anos) aprendeu Libras aos 13 anos de idade, com a chegada de uma professora surda fluente em sua escola. Apesar dos esforços, Pedro afirma que seu pai e sua mãe nunca desenvolveram fluência na Língua de Sinais e que muitas vezes se sentia isolado em sua própria casa. Mesma situação familiar vivenciada por Ana Paula (22 anos), com a diferença de que ela aprendeu Libras ainda na infância, nos primeiros anos de escolarização, tanto na escola, com uma professora surda, quanto na APADA. A situação de Júlia (11 anos) e de Marcela (12 anos) é diferente. Ambas aprenderam Libras muito pequenas, a partir dos três anos de idade, momento em que os pais descobrem sua surdez. Esse aprendizado pôde ser realizado inicialmente na APADA e depois na escola. As famílias de Júlia e de Marcela têm bom conhecimento da Língua Brasileira de Sinais.

Quanto aos seus processos de escolarização, Pedro inicialmente estudou em classe regular com colegas surdos e ouvintes, contexto no qual era utilizada a abordagem oralista. Somente mais tarde, com a chegada da professora surda, passa a estudar em uma classe especial para surdos, onde a Língua de instrução era a Libras. Ana Paula já inicia a escolarização na classe especial para surdos 
SILVA, Ivone Maria Mendes; REMOS, Silvia Salete. Direitos humanos e linguísticos e suas relações com a educação de surdos: reflexões a partir do diálogo com estudantes surdos fluentes em Libras

e apenas a partir do $6^{\circ}$ ano passa para a classe regular com a presença do intérprete de Libras; assim como Marcela, que estuda em uma escola com a mesma metodologia. Já Julia cursou do $1^{\circ}$ ao $4^{\circ}$ ano em uma classe especial e depois muda de escola. Na escola nova passa a frequentar uma classe regular com a presença de intérprete de Libras. Tanto Pedro quanto Ana Paula seguiram estudando. Pedro atualmente é pós-graduado e professor de Libras e Ana Paula, após concluir o Ensino Médio, cursa Técnico em Finanças.

Ao se posicionar sobre a importância da Língua de Sinais em sua vida, Pedro (31 anos) narra:

[...] eu prefiro que Libras porque é minha visão e minha mão abrir o meu mundo conhecimento que parece a minha chave é LIBRAS e depois vai aprenderei compreender que ler e escrever.

Percebemos nessa narrativa que a Libras tem sua importância destacada enquanto processo que faculta a construção de conhecimentos pelo sujeito surdo, sendo necessária inclusive para a aprendizagem da leitura e da escrita. O que é amplamente defendido por especialistas e pesquisadores do tema.

O uso da língua de sinais contribuiu em muito para a aprendizagem dos alunos surdos, já que, por ser visual-espacial, não oferece dificuldades para ser adquirida. Por meio dela, observou-se a ampliação do conhecimento de mundo e do conteúdo escolar e, para os surdos, filhos de pais ouvintes, abriu-se a possibilidade de aquisição de uma primeira língua (PEREIRA, 2014, p. 145).

O que Pedro narra também demonstra as possibilidades expressivas e comunicativas que a Libras proporcionou a ele. O que vai ao encontro dos achados obtidos por Peixoto (2006, p. 208) em sua pesquisa, ao constatar: "Para grande parte dos surdos, a linguagem evolui através da Língua de Sinais, que amplia as possibilidades cognitivas e conceituais para nomear e categorizar a realidade ao seu redor, bem como perpassa os objetos de conhecimento com o qual se deparam".

Seguindo essa linha de pensamento, Araujo (2010, p. 31) salienta que através da Libras o surdo pode criar formas de representar o mundo, pensar, interagir, estruturar o aprendizado de outras línguas, além de construir uma identidade própria, que se relaciona com sua diferença.

Para Ana Paula (22 anos), que assim como Pedro optou por dar continuidade aos estudos após a escolarização básica, a Libras parece ter possibilitado maior liberdade e independência, além de efetivar sua participação na cultura da comunidade surda e a afirmação de sua identidade.

A Libras é muito importante, porque sou surda para eu possa viajar o que eu quero fazer, como estudo, trabalho, família e etc... Por isso, eu comecei a perceber que é muito importante para mim, porque eu posso conhecer muito sobre comunidade surda para conversar com os surdos, cultura surda, comunidade surda e etc... Por isso, eu assumi a identidade surda porque eu nunca tinha vergonha de nada porque eu amo quem sou eu (ANA PAULA, 22 anos). 
SILVA, Ivone Maria Mendes; REMOS, Silvia Salete. Direitos humanos e linguísticos e suas relações com a educação de surdos: reflexões a partir do diálogo com estudantes surdos fluentes em Libras

A narrativa de Marcela ilustra também a importância do uso da Língua de Sinais para a construção de sua identidade, além de demonstrar que a fala/oralização para ela são uma imposição indesejada. A sua identificação com os surdos é tanta que ela gostaria que a sua família fosse como ela.

Minha vida normal, minha mãe sabe libras, meu pai e meu irmão sabem um pouco. Eu vou nos lugares sozinha, mas preciso escrever porque as pessoas não me entendem. Quando eu conheço a pessoa e sei que não sabe libras eu nem converso porque fica falando eu não entendo e não tenho paciência (MARCELA, 12 anos).

Se é pela linguagem que o ser humano pode vir a se apropriar dos produtos culturais e se beneficiar das experiências e conhecimentos de outras pessoas, a Libras, para os surdos, é o meio pelo qual podem participar ativamente da cultura de sua comunidade e do compartilhamento de informações presentes dentro dela (LOPES, 1998; SANTOS, 2012; ALVES, 2016).

Pedro, que no período inicial de escolarização vivenciou tentativas de oralização/normalização, revela que naquele momento não sabia ainda quem era e sofria com isso. Ao assumir-se surdo, encontrou na Libras um ponto de apoio, que acabou revelando-se um recurso precioso, justamente por despertar sua vontade de aprender.

Começa na escola eu não sei quem sou surdo e outros percebi uns meninos surdos iguais eu.... Mas verdade nunca saber o que sou surdo nada... Parece sou um normal e depois quando eu cresci que entendo sou surdo era não é normal... mas, me sinto é normal sim... e depois eu assumi surdo que eu amo LIBRAS também eu vontade aprender qualquer no mundo conhecimento viver (PEDRO, 31 anos).

Nesse sentido, complementa Lopes (1998), a aquisição da Língua de Sinais pelos surdos, bem como seu uso na convivência com os pares surdos ou com ouvintes pode fornecer a esses sujeitos recursos para a afirmação de suas identidades, bem como para o reconhecimento de sua diferença como singularidade e não como anormalidade. Processo esse que deve ocorrer desde cedo na vida das crianças surdas, tendo as diversas instâncias sociais uma responsabilidade grande de promovê-lo, em especial a escola. Discorrendo especificamente sobre a importância que a Libras pode assumir nas relações estabelecidas entre sujeitos surdos na escola, essa autora enfatiza: "as trocas culturais e de poderes desiguais entre surdos que compartilham de uma situação linguística semelhante auxiliam no processo de ocupação territorial escolar, na organização dos movimentos surdos, na convivência e na formação de comunidades surdas” (LOPES, 1998, p. 119).

A narrativa de Ana Paula (22 anos), ao falar sobre uma professora surda com quem conviveu ainda durante a educação básica, demonstra o importante papel que os professores 
SILVA, Ivone Maria Mendes; REMOS, Silvia Salete. Direitos humanos e linguísticos e suas relações com a educação de surdos: reflexões a partir do diálogo com estudantes surdos fluentes em Libras

podem desempenhar na inclusão de estudantes surdos nas escolas e como o estabelecimento de relações desse tipo tende a fortalecer a cultura e identidade surdas:

Eu estudava com os surdos na série 1 até 5 anos que ela era minha professora Surda e aprendi muito tudo por causa dela a professora me ensinava tudo o que ela precisava, até eu aprendi muitas coisas para histórias como Surdas, Cultura Surda, Comunidade Surda e etc.

Assim como Ana Paula, Pedro também relata identificação com a professora surda que chega na escola e lhe ensina uma nova língua, abrindo para ele uma infinidade de novas possibilidades. Ele reconhece que a chegada dessa professora surda fez com que a escola se tornasse um lugar mais atrativo para ele. Associado a isso, o aprendizado da Língua de Sinais permitiu que experimentasse uma liberdade até então desconhecida.

Os relatos de Ana Paula e Pedro endossam o que destaca Silva (2017) ao argumentar que a mediação feita por professores surdos contribui para a aquisição da Língua de Sinais e para a construção das identidades dos estudantes surdos por meio das trocas culturais que ocorrem nessa mediação.

Quando mediada por professoras surdas ou professores surdos, a aquisição de língua de sinais por crianças surdas na escola ocorre associada à construção das identidades surdas, visto que, através das trocas culturais no processo ensinoaprendizagem entre esses pares, outros artefatos culturais como a história, os hábitos, as crenças e os direitos sociais desse grupo cultural circulam discursivamente, ou seja, nesse processo, traduzem a cultura surda (SILVA, 2017, p. 85).

Além de reconhecerem a importância das interações estabelecidas com outros surdos fluentes em Libras, os entrevistados chamaram atenção para o fato de que gostariam de se comunicar em Libras também com sujeitos ouvintes, seja na escola seja em outros contextos nos quais circulam na vida cotidiana. Júlia (11 anos) é a entrevistada que aborda de forma mais contundente essa questão, quando aponta, em sua narrativa, que a maioria dos alunos e professores da escola em que estudou até o $4^{\circ}$ ano do Ensino Fundamental não sabiam Libras e que, devido a isso, sentia-se isolada em alguns momentos. Relata também que, nesse contexto, onde a maioria ouvinte não mantinha qualquer contato com os alunos da classe especial para surdos, sentia-se insegura e com medo de que não a aceitassem e não gostassem dela por causa da sua diferença.

Assim, a perspectiva apresentada pelos entrevistados sobre a forma como essas questões têm sido significadas e abordadas na/pela escola, por diversos atores sociais que a compõem, precisa ser problematizada com vistas à construção das mudanças que se fazem necessárias para a consolidação dessa instituição como um espaço democrático, pois ainda coexistem nela práticas e valores contraditórios, que apontam para diferentes direções. No caso dos nossos entrevistados, 
SILVA, Ivone Maria Mendes; REMOS, Silvia Salete. Direitos humanos e linguísticos e suas relações com a educação de surdos: reflexões a partir do diálogo com estudantes surdos fluentes em Libras

ao mesmo tempo em que a escola desponta como lugar de pertencimento (como no caso em que Ana Paula e Pedro veem na professora surda uma fonte de identificação), também é experimentada como espaço onde sua diferença linguística não é respeitada e valorizada como poderia, pois são poucas as pessoas que, nesse contexto, conhecem a língua sinalizada. A maioria se atém à comodidade da língua oral. Isso faz com que o surdo permaneça dentro de um grupo restrito de interlocutores, composto por aqueles que compartilham de sua língua e de sua cultura, porque se torna mais difícil o processo de participar dos demais contextos presentes na escola e na sociedade.

As narrativas dos estudantes surdos com os quais tivemos contato ao longo dessa pesquisa deixam entrever, ainda, que o aprendizado e uso da Língua de Sinais representam um direito cujo usufruto é de suma importância em suas vidas, pois repercute no exercício de outros direitos fundamentais (educacionais, culturais, políticos etc.). Não obstante os aspectos positivos identificados pelos entrevistados, fica evidenciada a necessidade de haver uma maior difusão e valorização da Libras nas/pelas escolas, assim como em outros espaços públicos, para que esses significados positivos a ela associados se transformem em realidade acessível a mais pessoas. Processo que depende não apenas de atos isolados ou pontuais, assumidos por indivíduos, mas de mudanças sociais e políticas de longo alcance e profundidade. Isso porque, como lembra Bobbio (1992), a concretização dos direitos humanos é uma questão “cuja solução depende de um certo desenvolvimento da sociedade" (BOBBIO, 1992, p. 45).

\section{Considerações finais}

A pesquisa aqui apresentada evidenciou que a Língua de Sinais cumpre papel fundamental na construção identitária dos sujeitos surdos e na relação que estes estabelecem com a construção de conhecimentos, seja no âmbito escolar seja em outros contextos de vida.

Desse modo, a Libras constitui muito mais do que um modo de comunicação para esses sujeitos. Além de possibilitar-lhes o acesso aos conteúdos escolares, ela atua como um recurso que amplia sua capacidade de atribuir significação a tudo que os rodeia no mundo em que vivem, já que é uma língua completa e que permite a expressão de pensamentos e emoções. Conforme atestam as narrativas dos participantes da pesquisa, seu uso na vida cotidiana confere ainda maior autonomia e independência ao surdo, auxiliando-o no trânsito entre diferentes territórios, grupos, culturas e saberes.

A Libras também contribui para que os sujeitos surdos tenham consciência da sua diferença e de que essa diferença não se constitui em incapacidade, mas sim em uma maneira diferente de ser e de viver. Nota-se que quanto mais difundido e valorizado é o uso da Língua de Sinais nos 
SILVA, Ivone Maria Mendes; REMOS, Silvia Salete. Direitos humanos e linguísticos e suas relações com a educação de surdos: reflexões a partir do diálogo com estudantes surdos fluentes em Libras

diferentes contextos de vida dos quais participam os surdos, maiores são as chances de que eles venham a significar positivamente a surdez e alcançar o desenvolvimento de suas potencialidades. Isso porque é através das relações vivenciadas nesses contextos que os sujeitos surdos irão construir suas identidades, tecendo aprendizagens múltiplas sobre si mesmos e sobre o mundo.

A escola é um desses contextos e tem muito a oferecer à formação dos sujeitos surdos. Todavia, sua consolidação como instituição democrática requer a problematização e combate das práticas de caráter excludente que ainda hoje são perpetradas em seu interior e que guardam relação com outras formas de discriminação e opressão que atravessam o tecido social como um todo. Nesse espaço, como em outros de nossa sociedade, mudanças são requeridas para o reconhecimento e legitimação não apenas dos direitos linguísticos dos surdos, mas dos direitos educacionais, políticos e culturais de todos os cidadãos brasileiros.

\section{Referências}

ALVES, Francisco das Chagas Fernandes. Discursos dos docentes ouvintes de surdos sobre cultura, língua de sinais e identidade surda em uma escola bilingüe. 2016. 90 f. Dissertação (Mestrado em Educação) Universidade Federal da Paraíba, João Pessoa, 2016. Disponível em: <https://repositorio.ufpb.br/jspui/handle/tede/9905> Acesso em: 01 nov. 2018.

ARAUJO, Maria Tereza Abrahao de. Alfabetização e letramento: o aprendizado da língua portuguesa por sujeitos surdos. 2010. Dissertação (Mestrado em estudos linguísticos) - Universidade Federal de Minas Gerais, Minas Gerais, 2010.Disponível em: <http://www.bibliotecadigital.ufmg.br/dspace/handle/1843/LETR-8TBSG5>.Acesso em:17out. 2018.

BARDIN, Laurence. Análise de conteúdo. 70. ed. São Paulo, 2016.

BOBBIO, Norbert. Qual socialismo? Rio de Janeiro: Paz e Terra, 1983.

BOBBIO, Norbert. A era dos direitos. Rio de Janeiro: Campus, 1992.

BOBBIO, Norbert. Teoria Geral da Política. Rio de Janeiro: Campus, 2001.

BOTO, Carlota. A educação escolar como direito humano de três gerações: identidades e universalismos. Educação \& Sociedade, 2005, vol.26, n.92, pp.777-798.

BRASIL. Presidência da República. Lei n 13. 146 de 6 de julho de 2015. Institui a lei brasileira de inclusão da pessoa com deficiência (Estatuto da pessoa com deficiência). Brasília. 2015. Disponível em: <http://www.punf.uff.br/inclusao/images/leis/lei_13146.pdf>. Acesso em: 14 jul. 2018.

BRASIL. Presidência da República. Lei n 10.436 de 24 de abril de 2002. Dispõe sobre a Língua Brasileira de Sinais - Libras e dá outras providências. Brasília. 2002. Disponível em:< http://www.planalto.gov.br/ccivil_03/leis/2002/110436.htm>. Acesso em: 30 mai. 2018. 
SILVA, Ivone Maria Mendes; REMOS, Silvia Salete. Direitos humanos e linguísticos e suas relações com a educação de surdos: reflexões a partir do diálogo com estudantes surdos fluentes em Libras

BRASIL. Presidência da República. Decreto 5.626 de 22 de dezembro de 2005. Regulamenta a lei $\mathrm{n}^{\circ} 10.436$ de 24 de abril de 2002 que dispõe sobre a língua brasileira de sinais- Libras e o art. 18 da lei 10.098 de 19 de dezembro de 2000. Brasília. 2005. Disponível em:

<http://www.planalto.gov.br/ccivil_03/_ato2004-2006/2005/decreto/d5626.htm>. Acesso em: 30 mai. 2018.

BRASIL. Instituto Brasileiro de Geografia e Estatística (IBGE). Censo Demográfico 2010: características gerais da população. Rio de Janeiro: IBGE, 2012.

GOMES, Romeu. Análise e interpretação de dados de pesquisa qualitativa. In: DESLANDES, Suely Ferreira; GOMES, Romeu; MINAYO, Cecília de Souza (orgs). Pesquisa Social teoria, método e criatividade. Petrópolis. RJ: Vozes, 2012.

GOMES, Romeu et al. As arranhaduras da masculinidade: uma discussão sobre o toque retal como medida de prevenção do câncer prostático. Ciênc. saúde coletiva, vol.13 n. 6. Rio de Janeiro Nov./Dec. 2008. Disponível em:

$<$ http://www.scielo.br/scielo.php?script=sci_arttext\&pid=S1413-

81232008000600033\&lng=en\&nrm=iso > . Acesso em: 18 nov. 2018.

LOPES, Maura Corcini. Relações de poderes no espaço multicultural da escola para surdos. In: SKLIAR, Carlos (org). A Surdez: um olhar sobre as diferenças. [s. 1]: Mediação, 1998.

PEIXOTO, Renata Castelo. Algumas considerações sobre a interface entre a língua brasileira de sinais (Libras) e a língua portuguesa na construção inicial da escrita pela criança surda. Cad. Cedes, Campinas, vol. 26, n. 69, p. 205-229, maio/ago. 2006. Disponível em: < http://www.cedes.unicamp.br>. Acesso em: 20 out. 2018.

PEREIRA, Maria Cristina da Cunha. O ensino de português como segunda língua para surdos: princípios teóricos e metodológicos. Educar em revista, Curitiba, spe-2, p. 143-157, 2014. Disponível em: <http://www.scielo.br/scielo.php?script=sci_arttext\&pid=S0104$40602014000600011 \& \operatorname{lng}=$ en\&nrm=iso $>$. Acesso em: 31 maio 2018.

RODRIGUES, Carlos Henrique; BEER, Hanna. Direitos, Políticas e Línguas: divergências e convergências na/da/para educação de surdos. Educ. Real. vol.41 no.3 Porto Alegre jul./set. 2016. Disponível em: <http://www.scielo.br/scielo.php?script=sci_arttext\&pid=S217562362016000300661\&lng=pt\&nrm=iso\&tlng=pt > Acesso em: 10 mar. 2020.

SANTOS, Taiane Santos dos. Narrativas Surdas: experiências na comunidade e na cultura surda e a constituição de identidades. 2012. 117 f. Dissertação (Mestrado em Educação) - Universidade Federal de Pelotas, Pelotas, 2012.

SILVA, Lucas Romário da. Pedagogia surda: o papel de professoras surdas na construção de identidades de alunas surdas e alunos surdos. Dissertação (mestrado em educação) Universidade Federal da Paraíba. João Pessoa, 2017. Disponível em: $<$ https://repositorio.ufpb.br/jspui/bitstream/tede/9863/2/Arquivototal.pdf $>$. Acesso em: 17 out. 2018. 


\section{Dialogia}

SILVA, Ivone Maria Mendes; REMOS, Silvia Salete. Direitos humanos e linguísticos e suas relações com a educação de surdos: reflexões a partir do diálogo com estudantes surdos fluentes em Libras

Recebido em: 31 mar. 2020/ Aprovado em: 06 jul. 2020

\section{$\underline{\text { Cite como }}$}

\section{(ABNT NBR 6023:2018)}

SILVA, Ivone Maria Mendes; REMOS, Silvia Salete. Direitos humanos e linguísticos e suas relações com a educação de surdos: reflexões a partir do diálogo com estudantes surdos fluentes em Libras. Dialogia, São Paulo, n. 35, p. 122-134, maio/ago. 2020. Disponível em: https://doi.org/10.5585/dialogia.n35.16925.

\section{American Psychological Association (APA)}

Silva, I. M. M., \& Remos, S. S. (2020, maio/ago.). Direitos humanos e linguísticos e suas relações com a educação de surdos: reflexões a partir do diálogo com estudantes surdos fluentes em Libras. Dialogia, São Paulo, 35, p. 122-134. https://doi.org/10.5585/dialogia.n35.16925. 